\title{
Intermediate Cell Type Choroid Melanoma
}

National Cancer Institute

\section{Source}

National Cancer Institute. Intermediate Cell Type Choroid Melanoma. NCI Thesaurus.

Code C6100.

Choroid melanoma characterized by the presence of intermediate cells which are similar to but smaller than epithelioid cells. 